\title{
Prenatal care of women who give birth to children with fetal alcohol spectrum disorder in a universal health care system: a case-control study using linked administrative data
}

\author{
Deepa Singal PhD, Marni Brownell PhD, Elizabeth Wall-Wieler PhD, Dan Chateau PhD, \\ Ana Hanlon-Dearman MD, Sally Longstaffe MD, Leslie L. Roos PhD
}

\section{Abstract}

Background: Few studies have investigated prenatal care use among women who use alcohol during pregnancy. The objective of this study was to investigate rates of prenatal care usage of women who have given birth to children with fetal alcohol spectrum disorder (FASD).

Methods: We conducted a case-control study of women with children born in Manitoba between Apr. 1, 1984, and Mar. 31, 2012, with follow-up until 2013, using linkable administrative data. The study group included women whose child(ren) was (were) diagnosed with FASD $(n=702)$ between Apr. 1, 1999, and Mar. 31, 2012, at a centralized diagnostic clinic. The comparison group included women whose child(ren) did not have an FASD diagnosis $(n=2097)$, exact matched on the index child's birthdate, postal code and socioeconomic status. Adequacy of prenatal care was defined using the Revised Graduated Prenatal Care Utilization Index.

Results: Women in the study group had lower socioeconomic status than women in the comparison group and were more likely to have mental disorders and involvement with the child welfare system. Rates of inadequate prenatal care were higher among women in the study group (adjusted relative risk 2.47, 95\% confidence interval [Cl] 2.08-2.94), as were rates of no prenatal care (adjusted relative risk $3.55,95 \% \mathrm{Cl} 2.42-5.22$ ). In the study group, $41 \%$ of women accessed inadequate or no prenatal care, and $59 \%$ received intermediate, adequate or intensive prenatal care.

Interpretation: Women who give birth to children with FASD have higher rates of inadequate prenatal care and significant social complexities. Socioeconomic disparities in the use of prenatal care should be addressed; multisector interventions are needed that facilitate the uptake of prenatal care by high-risk women who use alcohol.

\section{A} lmost $10 \%$ of women around the world report consuming alcohol during pregnancy, which can lead to fetal alcohol spectrum disorder (FASD) in children. ${ }^{1}$ FASD is a diagnostic term that describes numerous symptoms and disabilities resulting from prenatal alcohol exposure, ${ }^{2}$ including facial dysmorphology, growth restriction, intellectual disabilities and social and behavioural difficulties that persist throughout the lifespan..$^{2-4}$ The global incidence of FASD has been estimated to be 1 in every 100 live births ${ }^{5}$ and significantly higher in vulnerable populations. ${ }^{6-8}$ The lifelong impact of this disorder makes FASD a global public health concern and significant clinical and policy challenge.

Physicians delivering prenatal health care (PNC) services to women are in a unique position to help prevent or reduce the amount of alcohol consumed during pregnancies and can play an integral role in decreasing the prevalence of FASD.
PNC is often the first point of access of care for women of child-bearing age and a frequently used preventive health care service in countries that provide universal health care. ${ }^{9,10}$ Physicians delivering PNC should routinely screen for alcohol use in pregnancy, and when they identify pregnant patients who are consuming alcohol they should refer them to treatment and support programs and link them to community resources. PNC has been shown to be more effective if it

Competing interests: None declared.

This article has been peer reviewed.

Correspondence to: Deepa Singal, deepakapoorsingal@gmail.com CMAJ Open 2019. DOI:10.9778/cmajo.20180027 
begins in the first trimester of pregnancy and regular visits are continued throughout pregnancy. ${ }^{11}$ The International Charter on Prevention of FASD ${ }^{12}$ recognizes the importance of screening for at-risk alcohol use in women of child-bearing age in primary care settings. Recommendations by professional societies such as the American Congress of Obstetricians and Gynecologiests state that screening, brief intervention and referral to treatment should be implemented in general primary care and obstetric settings to reduce alcohol use during pregnancy. ${ }^{13}$ These interventions are particularly relevant in countries where there is access to universal health care, specifically free access to regular PNC, as cost can be a significant barrier to seeking care.

Few studies have investigated the actual rates of PNC utilization by women who have given birth to children with FASD. Documenting whether women who give birth to children with FASD access PNC and receive adequate PNC is the first step in investigating the potential role PNC settings can play in reducing prenatal alcohol use and ultimately the incidence of FASD. If screening programs in PNC settings are to be successful, it is imperative to know whether the women to whom these programs are targeted are actually using the health care service.

This study uses a population-based cohort from a country with a universal health care system to compare rates of PNC utilization among women whose child(ren) has (have) FASD with those of women whose child(ren) does (do) not have FASD.

\section{Methods}

\section{Study setting}

We conducted a retrospective analysis of the Manitoba Mothers and FASD Cohort, ${ }^{14}$ a population-based cohort of Manitoba women whose child(ren) was (were) born between Apr. 1, 1984, and Mar. 31, 2012, and diagnosed with FASD between Apr. 1, 1999, and Mar. 31, 2012. ${ }^{15}$ The FASD diagnosis data first became available in 1999, making this the earliest year in which we are able to identify children with FASD.

\section{Data sources}

This study used administrative health, social and educational data from the Population Research Data Repository housed at the Manitoba Centre for Health Policy (MCHP) and clinical assessment data from the Manitoba FASD Centre, which is the only referral/diagnostic centre for FASD in the province. ${ }^{15}$ The data set consists of children who have received a diagnosis of FASD, children who have been assessed but did not meet the criteria for an FASD diagnosis, and those who have received a deferred status, meaning that they will be assessed at a later time (e.g., when they are older and symptoms may be more apparent). Table 1 provides a description of all databases used in this study. ${ }^{15}$ Health records from the Ministry of Health are deidentified before being transferred to the MCHP repository. They remain linkable across multiple databases by way of scrambled personal health identification numbers. Rates of PNC utilization were obtained from
Manitoba Health's hospital discharge abstracts and medical/ physician reimbursement claims. The reliability and validity of the data in the MCHP repository have been well established, and the databases are widely used for health and social service research, ${ }^{16-19}$ including studies drawing on the Manitoba Mothers and FASD Cohort. ${ }^{14,20}$

\section{Study cohort}

Women included in this study were drawn from the entire Manitoba population of women who had a live birth in Manitoba between Apr. 1, 1984, and Mar. 31, 2012, and continued living in Manitoba until December 2013. ${ }^{15}$ This population generated 2 groups (Figure 1).

\section{Study group: Mothers whose children had received a clinical diagnosis of FASD}

We first identified all Manitoba children and youth (up to the age of $21 \mathrm{yr}$ ) who had been diagnosed with FASD between 1999 and 2012 using the Manitoba FASD Centre data ${ }^{15}$ and then identified their birth mothers by linking the Manitoba FASD Centre data to administrative health data in the repository. ${ }^{15} \mathrm{We}$ excluded women who were not residents of Manitoba and were therefore not covered by Manitoba's universal health care program during the period of 3 years before the birth of their child until March $2013,{ }^{15}$ as well as women whom we could not link to their children because of missing postal code information. ${ }^{15}$ See Figure 1 for more information on the study cohort.

\section{Comparison group: Mothers whose children had not received a clinical diagnosis of FASD}

The comparison group included women from the general population who had no evidence of prenatal alcohol use and whose child(ren) had no evidence of FASD according to data from the Manitoba FASD Centre and repository (see Figure 1 for exclusion criteria). We matched this group to the study group on the index child's birthdate, postal code of residence and socioeconomic status at a ratio of $3: 1,{ }^{15}$ using exact matching.

\section{Variables}

\section{Outcomes}

Physician claims and hospital discharge abstracts were used to assess the quantity and timing of PNC visits. The gestational age of the baby was obtained from the hospital birth record and physician claims files were used to identify the number and initiation of PNC visits. Pregnancy trimesters were defined as follows: the first trimester is from the date of conception to 91 days, the second trimester is from 92 to 189 days and the third trimester is from 190 days to the date of birth. The date of conception was calculated by subtracting the gestational age from the birthdate of the child. The following outcomes were calculated to investigate PNC utilization: (a) no care, (b) late initiation of PNC, (c) care initiated in the first trimester, (d) care initiated in the second trimester, (e) care initiated in the third trimester, (f) low number of 
Table 1: Description of data sets used for analysis

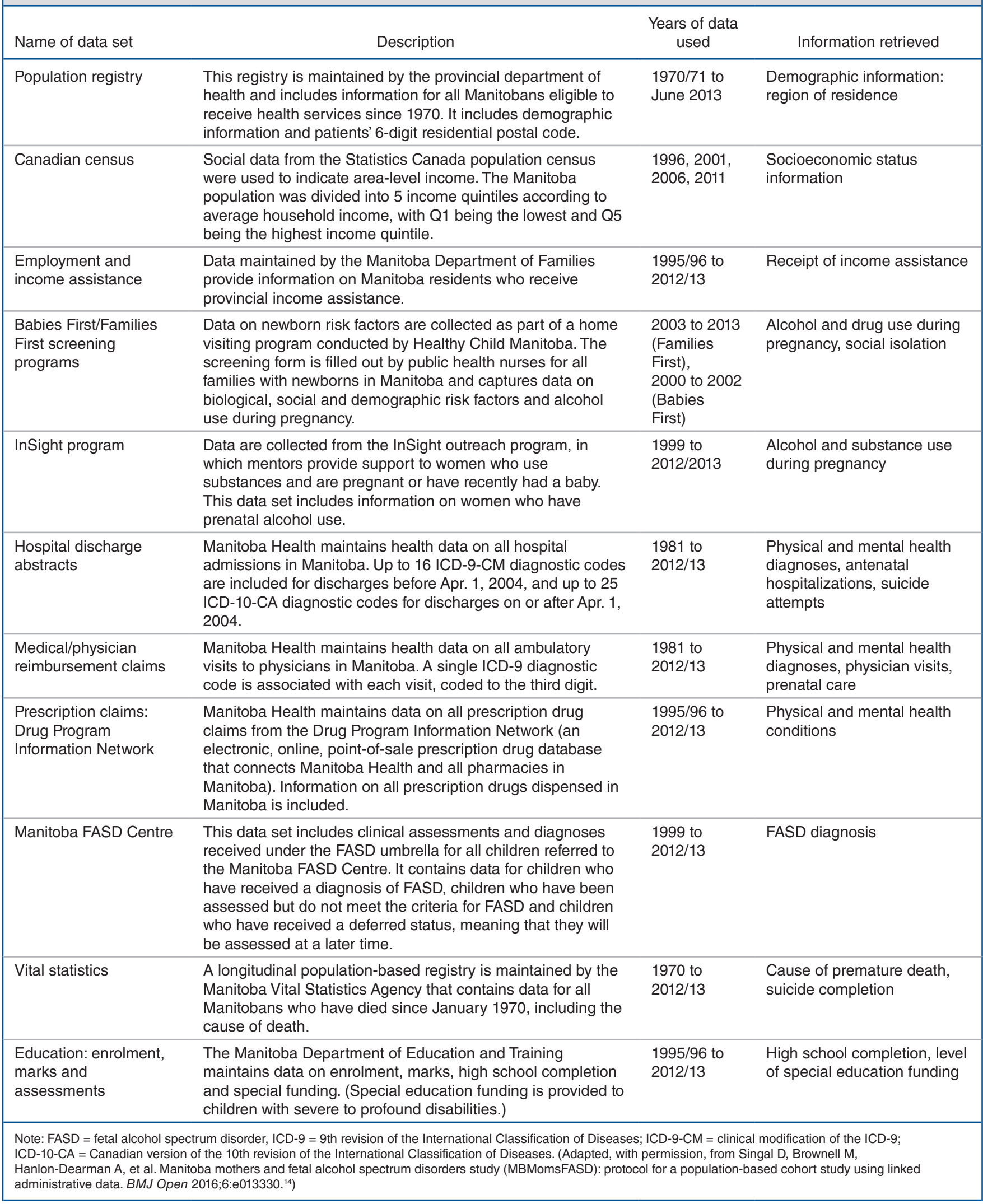




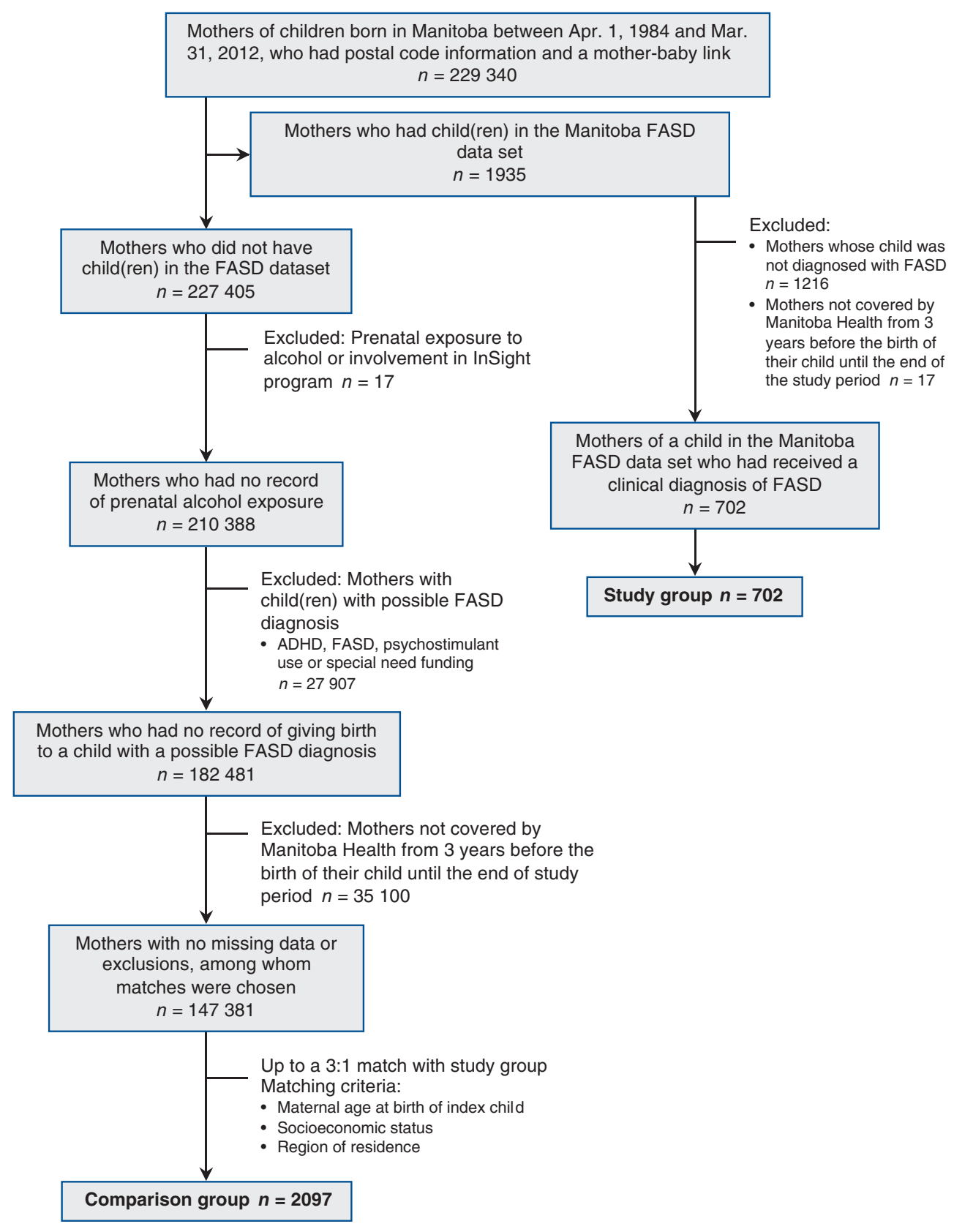

Figure 1: Study cohort formation. InSight is an intensive mentoring program for women who are pregnant or have recently had a baby and have issues with substance issue and are at high risk of having children with fetal alcohol spectrum disorder. Note: ADHD = attention-deficit hyperactivity disorder, FASD = fetal alcohol spectrum disorder.

prenatal visits and (g) adequacy of PNC (see Table 2 for definitions).

Adequacy of PNC was evaluated using the Revised Graduated Prenatal Care Utilization Index (R-GINDEX); this commonly used validated index is based on the full American
College of Obstetricians and Gynecologists guidelines., ${ }^{910,21,22}$ The R-GINDEX is derived using 3 variables: gestational age, the trimester in which care was initiated and the number of prenatal visits. Gestational age is obtained from the birth hospitalization discharge abstract, and prenatal care is derived 


\begin{tabular}{|c|c|}
\hline Outcome & Definition or method of calculation \\
\hline $\begin{array}{l}\text { Late initiation of prenatal } \\
\text { care }\end{array}$ & The woman's prenatal care began after the first trimester (date of conception to $91 \mathrm{~d}$ ) \\
\hline No care & The woman received no prenatal care in the first, second or third trimester \\
\hline $\begin{array}{l}\text { Care initiated in first } \\
\text { trimester }\end{array}$ & The woman's first prenatal visit was in the first trimester (date of conception to $91 \mathrm{~d}$ ) \\
\hline $\begin{array}{l}\text { Care initiated in second } \\
\text { trimester }\end{array}$ & The woman's first prenatal visit was in the second trimester (92-189 d) \\
\hline $\begin{array}{l}\text { Care initiated in third } \\
\text { trimester }\end{array}$ & The woman's first prenatal visit was in the third trimester (190 $d$ to date of birth) \\
\hline $\begin{array}{l}\text { Low number of prenatal } \\
\text { visits }\end{array}$ & The woman had fewer than 5 prenatal visits before delivery \\
\hline $\begin{array}{l}\text { Inadequate or no prenatal } \\
\text { care }\end{array}$ & The proportion of women with no or inadequate prenatal care was determined using the R-GINDEX. \\
\hline $\begin{array}{l}\text { Quality of prenatal care by } \\
\text { the R-GINDEX }\end{array}$ & $\begin{array}{l}\text { The R-GINDEX is a measure of the adequacy of prenatal care by a health care provider that identifies } 6 \\
\text { major categories of prenatal care: inadequate prenatal care, intermediate prenatal care, adequate prenatal } \\
\text { care, intensive care, no care and missing information. }{ }^{10} \text { Knowledge of } 3 \text { birth-related outcomes is required } \\
\text { to calculate the R-GINDEX: } \\
\text { - the gestational age of the infant (date of pregnancy and birth) as calculated from the hospital abstract }{ }^{10} \text {; } \\
\text { - the trimester during which prenatal care began, using hospital abstracts and physician claims data (the } \\
\text { ICD-9-CM tariffs that were included are } 8400,8401,8501,8507,8509,8529,8540,8550^{10} \text { ); and } \\
\text { - the total number of prenatal visits during pregnancy as calculated from hospital abstracts and physician } \\
\text { claims. }^{10}\end{array}$ \\
\hline Inadequate PNC & The proportion of women with inadequate prenatal care was determined using the R-GINDEX. \\
\hline Intermediate PNC & The proportion of women with intermediate prenatal care was determined using the R-GINDEX. \\
\hline Adequate PNC & The proportion of women with adequate prenatal care was determined using the R-GINDEX. \\
\hline Intensive PNC & $\begin{array}{l}\text { The proportion of women with intensive prenatal care was determined using the R-GINDEX. Women whose } \\
\text { number of visits was approximately } 1 \text { standard deviation above the mean number of visits for other women } \\
\text { whose prenatal care was initiated in the same trimester and whose baby was the same gestational age at } \\
\text { delivery were labelled as intensive care users. }{ }^{10} \text { "These women had an unexpectedly large number of PNC } \\
\text { visits, which may indicate potential morbidity or complications." }{ }^{10}\end{array}$ \\
\hline No care & The proportion of women with no prenatal care in any trimester was determined using the R-GINDEX. \\
\hline
\end{tabular}

from physician claims. These 3 variables are used to categorize PNC into 6 distinct groups: (a) no care, (b) inadequate care, (c) intermediate care, (d) adequate care, (e) intensive care and (f) missing. ${ }^{10}$ For example, for a woman who began prenatal care in her first trimester and gave birth at 40 weeks gestation, 1-7 prenatal care visits is considered inadequate care, 8-12 visits is considered intermediate care, $13-16$ visits is considered adequate care and 17 or more visits is considered intensive care. ${ }^{21}$ These 6 categories of care are used consistently across different measures of PNC as they provide accurate measurements of PNC utilization; this is critical for monitoring trends and assessing potential relationships., ${ }^{9}, 10,12,22$

\section{Covariates}

The following covariates were selected on the basis of clinical relevance and were adjusted for in each of the outcome models: region of residence, date of birth of index child and socioeconomic status. Socioeconomic status was defined using area-level (available at the dissemination area level, which is approximately 400-700 individuals ${ }^{23}$ ) mean household income from census information and grouped into quintiles ranked from 1 (low) to 5 (high), with approximately $20 \%$ of the population assigned to each quintile. ${ }^{24}$

\section{Analysis}

A summary data set for the total number of events (e.g., total number of mothers with inadequate $\mathrm{PNC}$ ) was produced to model the rate of PNC utilization comparing the study and comparison groups. We modelled adjusted relative rates of PNC utilization using generalized linear models with a Poisson or negative binomial distribution. This type of model is suitable for non-normally distributed data such as counts. We adjusted for covariates tested for differences between the study group and comparison group. The log of the population was included as an offset in the model to generate a relative rate versus a relative count of events. For the Poisson distribution we used a robust variance estimator proposed by LiangZeger. ${ }^{25}$ Administrative data are not collected for research 
purposes; therefore, we could not include various confounding variables present in the literature that are known to affect women accessing health care services, including limited transportation and feelings of stigma or fear. To address this limitation, gamma sensitivity analysis was conducted to measure how strong an unmeasured confounder would have to be to nullify statistically significant results. ${ }^{26,27}$

\section{Ethics approval}

This study was approved by the University of Manitoba's Health Research Ethics Board (HS16460[H2013:221]) and the Manitoba Health Information Privacy Committee (HIPC no. 2013/2014-20).

\section{Results}

Our study population consisted of women who were born between 1946 and 1992, with ages ranging from 14 to 46 years (Table 3). Most of the women from both groups were from an urban location and had a wide variety of social and health complexities (Table 3). Women in our study group had low socioeconomic status; $19 \%$ had a history of receiving income assistance before the birth of the child, indicating the considerable level of poverty present in this cohort. Women in the study group were also more likely to be lone parents, more likely to have higher gravidity and parity and more likely to have mental health disorders than women in the comparison group.

\section{Prenatal care utilization}

Thirty-three percent of the study group had inadequate PNC and $8.12 \%$ had no PNC, whereas $14 \%$ and $2 \%$ of our comparison group had inadequate and no PNC, respectively (Table 4). When we adjusted for maternal age, region of residence and socioeconomic status, our study group had over 2 times the rate of inadequate PNC (adjusted relative rate 2.47, 95\% confidence interval [CI] 2.08-2.94) and over 3 times the rate of no PNC versus our comparison group (adjusted relative rate $3.55,95 \%$ CI 2.42-5.22). Women in the study group also had higher rates of the following: PNC that was initiated in the second trimester (adjusted relative rate 1.69, 95\% CI 1.35-2.13), late/no initiation of care (adjusted relative rate 1.69, 95\% CI 1.39-2.04), low number of prenatal visits (adjusted relative rate 3.15, 95\% CI 2.59-3.83), intermediate PNC (adjusted relative rate 1.62, 95\% CI 1.34-1.94) and inadequate/no PNC (adjusted relative rate 2.63, 95\% CI 2.25-3.08). Despite the high rates of inadequate or no prenatal care, $59 \%$ of women in the study group did receive intermediate, adequate or intensive PNC.

\section{Gamma sensitivity analysis}

Sensitivity analyses found that all of the models generating rates of quality and frequency of prenatal care were reasonably robust to unmeasured confounding (Table 4), including late or no initiation of care and all levels of quality of PNC measured by the R-GINDEX. Hence, the likelihood of confounders existing, after adjustment for covariates included in the models, that would nullify the direction and significance of our results is small. However, the sensitivity measure regarding care initiated in the first trimester may be more sensitive to unmeasured confounding and could potentially become nonsignificant if there were very strong unmeasured confounders for which we were unable to account. The findings regarding care initiated in the third trimester were quite sensitive to unmeasured confounding, which is a limitation; however, neither of these situations would weaken the overall findings from these analyses.

\section{Interpretation}

Women who give birth to children with FASD often receive inadequate PNC. Over a third (41\%) of women in the study group received inadequate or no PNC, compared with just over $15 \%$ of women in the comparison group. Study findings also indicate that women who give birth to children with FASD have increased social complexities, including lone parenthood, low socioeconomic status, higher gravidity and parity and higher rates of mental health disorders. ${ }^{20,28}$ These social complexities may affect the way they access prenatal care. These results suggest that screening and intervention programs implemented in PNC settings may miss a population at extremely high risk for alcohol use during pregnancy. Within FASD prevention strategies focusing on prenatal care, it may be useful to implement outreach efforts developed to reduce the inequities in access to and use of prenatal care by women who may be harder to reach. ${ }^{29}$

Despite the high proportion of inadequate PNC in the study group, $59 \%$ of women who have given birth to a child with FASD received adequate, intensive or intermediate PNC and consumed alcohol throughout their pregnancy. Results of this study therefore also demonstrate that a significant proportion of women who give birth to children with FASD do access regular PNC, identifying an important target for alcohol prevention and reduction interventions.

These study results are consistent with the few previous studies in this area. ${ }^{30-33}$ All of the previous studies reported that women who give birth to children with FASD receive less $\mathrm{PNC}$ than women in comparison groups and generally begin PNC later in their pregnancies. ${ }^{30-33}$ Previous studies were limited by the use of small sample sizes generated from high-risk populations and were not conducted in countries with universal access to health care. The model of health care delivery is an important factor when investigating health care utilization, as lack of health care insurance and inability to pay for health services are significant barriers to accessing regular care. Moreover, cultural differences between women in high-risk conditions may preclude the generalization of study results to women in general populations. Furthermore, measures used to assess the frequency of PNC visits in previous studies were not standardized, potentially resulting in biases when calculating the frequency of care received by women.

This study adds to the international literature by contributing data from a large North American sample of women who have access to universal PNC and by employing a novel analysis that uses a standardized index to evaluate PNC utilization. Through the use of this index we can 


\begin{tabular}{|c|c|c|}
\hline Characteristic & $\begin{array}{c}\text { Study group, } \\
\text { no. }(\%)^{*} \\
n=702\end{array}$ & $\begin{array}{c}\text { Comparison } \\
\text { group, no. }(\%)^{*} \\
n=2097\end{array}$ \\
\hline \multicolumn{3}{|l|}{ Maternal age at birth of index child, yr } \\
\hline Mean \pm SD & $24.43 \pm 6.14$ & $29.24 \pm 5.69$ \\
\hline Range & $14-43$ & $14-46$ \\
\hline \multicolumn{3}{|l|}{ Maternal age at birth of index child, yr } \\
\hline$<18$ & $72(10.3)$ & $231(11.0)$ \\
\hline $18-24$ & $333(47.4)$ & $831(39.6)$ \\
\hline $25-29$ & $146(20.8)$ & $525(25.0)$ \\
\hline $30-34$ & $96(13.7)$ & $367(17.5)$ \\
\hline$\geq 35$ and missing $\dagger$ & $55(7.8)$ & $143(6.8)$ \\
\hline \multicolumn{3}{|l|}{ Maternal age at first birth, yr } \\
\hline$<18$ & $266(37.9)$ & $246(11.7)$ \\
\hline $18-24$ & $340(48.4)$ & $854(43.1)$ \\
\hline $25-29$ & $54(7.7)$ & $530(25.3)$ \\
\hline $30-34$ & $29(4.1)$ & $306(14.6)$ \\
\hline$\geq 35$ and missing $\dagger$ & $13(1.9)$ & $112(5.3)$ \\
\hline History of teen pregnancy & $266(37.9)$ & $246(11.7)$ \\
\hline \multicolumn{3}{|l|}{ Region of residence } \\
\hline Rural & $251(35.8)$ & $764(36.4)$ \\
\hline Urban & $451(64.2)$ & $1333(63.6)$ \\
\hline \multicolumn{3}{|l|}{ Mean household income } \\
\hline Q1 (lowest) & $466(64.4)$ & $1398(66.7)$ \\
\hline Q2 & $104(14.8)$ & $312(14.9)$ \\
\hline Q3 & $57(8.1)$ & $171(8.2)$ \\
\hline Q4 & $36(5.1)$ & $108(5.2)$ \\
\hline Q5 (highest) & $26(3.7)$ & $78(3.7)$ \\
\hline Missing & $13(1.9)$ & $30(1.4)$ \\
\hline $\begin{array}{l}\text { Receipt of income assistance } 3 \mathrm{yr} \\
\text { before birth of the index child } \neq\end{array}$ & $63(18.3)$ & $98(9.6)$ \\
\hline \multicolumn{3}{|l|}{ Socioeconomic status } \\
\hline \multicolumn{3}{|l|}{ Income quintile } \\
\hline Low (Q1) & $466(66.4)$ & $1398(66.7)$ \\
\hline Middle (Q2 and Q3) & $161(22.9)$ & $483(23.0)$ \\
\hline High (Q4 and Q5) & $62(8.8)$ & $186(8.9)$ \\
\hline Missing & $13(1.9)$ & $30(1.4)$ \\
\hline Married at birth of child & $66(9.4)$ & $773(36.9)$ \\
\hline \multicolumn{3}{|l|}{ Gravidity } \\
\hline $0-3$ & $357(50.9)$ & $1966(93.8)$ \\
\hline$\geq 4$ & $306(43.6)$ & $113(5.4)$ \\
\hline Missing & $39(5.6)$ & $18(0.9)$ \\
\hline \multicolumn{3}{|l|}{ Parity } \\
\hline $0-3$ & $524(74.6)$ & $2063(98.4)$ \\
\hline$\geq 4$ & $139(19.8)$ & $16(0.8)$ \\
\hline Missing & $39(5.6)$ & $18(0.9)$ \\
\hline
\end{tabular}




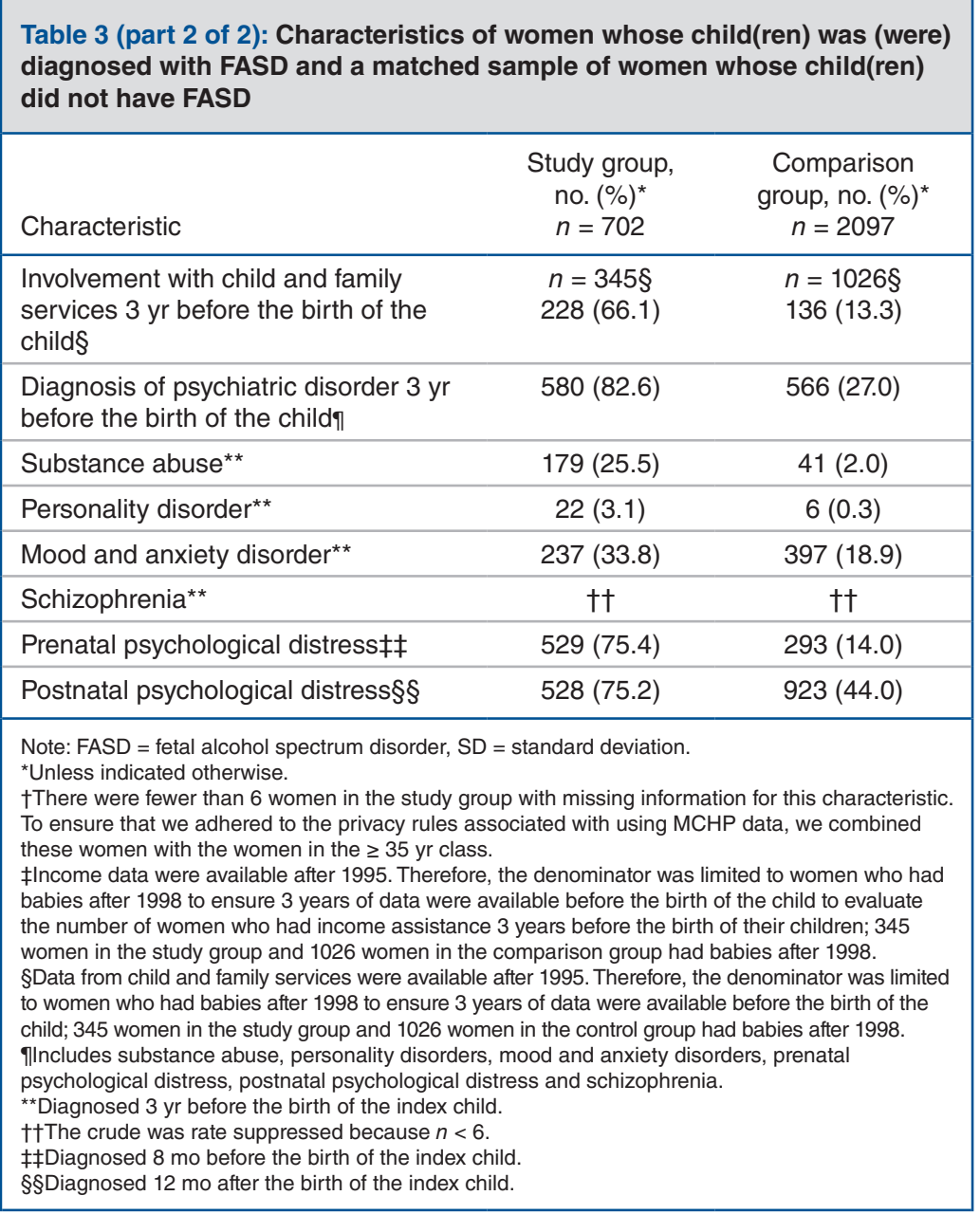

assess the varying degrees of PNC quality and utilization among our study sample, and we can assess not only whether women received inadequate care but also what proportions of them received adequate $\mathrm{PNC}$ and continued to consume alcohol during pregnancy. The use of administrative claims data in investigating PNC utilization by women who give birth to children with FASD strengthens the rigour of the study; these data are tremendously valuable for investigating the health care utilization of populations because their use eliminates important biases inherent in previous studies that used primary data collection methods, including nonresponse, recall and interviewer bias. Furthermore, by using clinical data from the Manitoba FASD Centre we ensured that our study group comprised women whose children have undergone a comprehensive multidisciplinary assessment in a central tertiary-level provincial diagnostic clinic that follows the Canadian guidelines for the diagnosis of FASD. ${ }^{2}$

Further investigation is warranted to examine how physicians approach PNC for women at risk for alcohol consumption during pregnancy (including screening, identifying and treating these at-risk women). Our results also indicate the need for further work to uncover the barriers and facilitators to PNC access for women with alcohol use and dependence issues, to develop effective outreach programs that make it easier for women at high risk for alcohol use during pregnancy to access PNC, and to develop programs and supports that help women to abstain from alcohol use during pregnancy.

\section{Limitations}

Although the data from the Manitoba FASD Centre provide good specificity, they provide uncertain sensitivity because women whose children are not referred to the clinic for assessment will be excluded from the study group. Although the centre receives referrals throughout the province, the cohort may be missing important subpopulations depending on the biases inherent in the referral process, thus limiting the generalizability of the findings. Although we were careful to exclude from the comparison group women who may have been exposed to alcohol prenatally and children with an FASD diagnosis, some women with unreported prenatal alcohol use or with children with undiagnosed FASD may still have been part of this group. However, this misclassification error would result in a more conservative estimate of the impact of using alcohol during pregnancy. Another potential limitation is that the number and time within the pregnancy of PNC visits were estimated from administrative claims files 


\begin{tabular}{|c|c|c|c|c|}
\hline \multirow[b]{2}{*}{ Outcome } & \multicolumn{2}{|c|}{ Crude rate (\%) } & \multirow[b]{2}{*}{ Adjusted RR $(95 \% \mathrm{Cl})^{*}$} & \multirow[b]{2}{*}{$\begin{array}{c}\text { Sensitivity to } \\
\text { unmeasured } \\
\text { confounding }\end{array}$} \\
\hline & $\begin{array}{c}\text { Women who } \\
\text { gave birth to a } \\
\text { child with FASD } \\
n=702\end{array}$ & $\begin{array}{l}\text { Women who did } \\
\text { not give birth to a } \\
\text { child with FASD } \\
\quad n=2097\end{array}$ & & \\
\hline \multicolumn{5}{|l|}{$\begin{array}{l}\text { Trimester in which care } \\
\text { was initiated }\end{array}$} \\
\hline First trimester & $536(76.4)$ & $1798(85.7)$ & $0.88(0.81-0.97)$ & 17.9 \\
\hline Second trimester & $116(16.5)$ & $209(10.0)$ & $1.69(1.35-2.13)$ & 56.9 \\
\hline Third trimester & $33(4.7)$ & $65(3.1)$ & $1.54(1.02-2.35)$ & 4.1 \\
\hline Late or no initiation of PNC & $166(23.7)$ & $299(14.3)$ & $1.69(1.39-2.04)$ & 63.8 \\
\hline Low number of PNC visits & $209(29.8)$ & $200(9.5)$ & $3.15(2.59-3.83)$ & 83.1 \\
\hline \multicolumn{5}{|l|}{$\begin{array}{l}\text { Quality of PNC care } \\
\text { as determined by the } \\
\text { R-GINDEX }\end{array}$} \\
\hline Inadequate PNC & $234(33.3)$ & $287(13.7)$ & $2.47(2.08-2.94)$ & 80.9 \\
\hline Intermediate PNC & $175(24.9)$ & $327(15.6)$ & $1.62(1.34-1.94)$ & 61.8 \\
\hline Adequate PNC & $113(16.1)$ & $399(19.0)$ & $0.84(0.68-1.04)$ & NS \\
\hline Intensive PNC & $123(17.5)$ & $1036(49.4)$ & $0.35(0.29-0.43)$ & 82.0 \\
\hline No PNC & $57(8.1)$ & $48(2.2)$ & $3.55(2.42-5.22)$ & 69.7 \\
\hline Inadequate or no PNC & $291(41.5)$ & $335(16.0)$ & $2.63(2.25-3.08)$ & 87.3 \\
\hline
\end{tabular}

and these estimates rely on the accuracy of physician coding. There may be missing PNC records in hospital or physician charts, and data from health care providers who do not submit claims for PNC may be missed. However, as previously stated, the data in the MCHP repository have been extensively validated for health services research, and therefore missing data are expected to have a practically negligible effect on the outcomes of this study. ${ }^{10,16-19,34,35}$ Although we controlled for socioeconomic status, the date of birth of the index child, and region of residence, there may be additional covariates that we did not account for. Another possible limitation of our study is that we were not able to determine if physicians had screened patients for alcohol use during pregnancy or counselled these women about the importance of refraining from alcohol use during pregnancy. Although universal screening for substance use during pregnancy is recommended, not all women are screened during their PNC visits as physicians may be inadequately trained to screen for prenatal alcohol use and may question the likelihood that women will reduce their alcohol use. Physicians may also be unaware of how to help their patients or connect them with resources if they do discuss alcohol use. Pregnant women may also be reluctant to disclose alcohol use during pregnancy because they may fear stigma and judgment and they may be afraid that they will lose their children to child welfare services.

\section{Conclusion}

Women who give birth to children with FASD have higher rates of inadequate $\mathrm{PNC}$ as well as higher rates of social complexities including poverty, mental health issues and involvement with child welfare services. Multisector interventions that address the social determinants of health are needed to facilitate access to prenatal care for vulnerable women who consume alcohol. A substantial percentage of the women in this study who used alcohol during pregnancy did receive adequate $\mathrm{PNC}$ and consumed enough alcohol to affect the fetus, highlighting an important need for additional research to better understand the quality of PNC and the opportunities to reduce or eliminate alcohol consumption through this health service.

\section{References}

1. Popova S, Lange S, Probst C, et al. Estimation of national, regional, and global prevalence of alcohol use during pregnancy and fetal alcohol syndrome: a systematic review and meta-analysis. Lancet Glob Health 2017;5:e290-9.

2. Cook JL, Green CR, Lilley CM, et al.; Canada Fetal Alcohol Spectrum Disorder Research Network. Fetal alcohol spectrum disorder: a guideline for diagnosis across the lifespan. CMA7 2016;188:191-7.

3. Burd L, Cotsonas-Hassler TM, Martsolf JT, et al. Recognition and management of fetal alcohol syndrome. Neurotoxicol Teratol 2003;25:681-8.

4. Pei J, Job J, Kully-Martens K, et al. Executive function and memory in children with fetal alcohol spectrum disorder. Child Neuropsychol 2011;17:290-309.

5. Roozen S, Peters GJ, Kok G, et al. Worldwide prevalence of fetal alcohol spectrum disorders: a systematic literature review including meta-analysis. Alcobol Clin Exp Res 2016;40:18-32. 
6. May PA, de Vries MM, Marais AS, et al. The continuum of fetal alcohol spectrum disorders in four rural communities in South Africa: prevalence and characteristics. Drug Alcohol Depend 2016;159:207-18.

7. May PA, Baete A, Russo J, et al. Prevalence and characteristics of fetal alcohol spectrum disorders. Pediatrics 2014;134:855-66.

8. May PA, Blankenship J, Marais AS, et al. Approaching the prevalence of the full spectrum of fetal alcohol spectrum disorders in a South African populationbased study. Alcohol Clin Exp Res 2013;37:818-30.

9. Alexander GR, Kotelchuck M. Assessing the role and effectiveness of prenatal care: history, challenges, and directions for future research. Public Health Rep 2001;116:306-16.

10. Heaman MI, Newburn-Cook CV, Green CG, et al. Inadequate prenatal care and its association with adverse pregnancy outcomes: a comparison of indices. BMC Pregnancy Childbirth 2008;8:15.

11. Healthy People 2010 final review. Hyattsville (MD): National Center for Health Statistics; 2012. Available: https://www.cdc.gov/nchs/data/hpdata2010/ hp2010_final_review.pdf (accessed 2016 Feb. 26).

12. Jonsson E, Salmon A, Warren KR. The international charter on prevention of fetal alcohol spectrum disorder. Lancet Glob Health 2014;2:e135-7.

13. Moyer A, Finney JW. Brief interventions for alcohol misuse. CMA7 2015; 187:502-6.

14. Singal D, Brownell M, Hanlon-Dearman A, et al. Manitoba mothers and fetal alcohol spectrum disorders study (MBMomsFASD): protocol for a populationbased cohort study using linked administrative data. BM7 Open 2016; 6:e013330.

15. Singal D, Brownell M, Hanlon-Dearman A, et al. Manitoba mothers and fetal alcohol spectrum disorders study (MBMomsFASD): protocol for a populationbased cohort study using linked administrative data. BMF Open 2016; 6:e013330.

16. Jutte DP, Roos LL, Brownell MD. Administrative record linkage as a tool for public health research. Annu Rev Public Health 2011;32:91-108.

17. Roos LL, Gupta S, Soodeen RA, et al. Data quality in an information-rich environment: Canada as an example. Can f Aging 2005;24(Suppl 1):153-70.

18. Roos LL, Menec V, Currie RJ. Policy analysis in an information-rich environment. Soc Sci Med 2004;58:2231-41.

19. Roos LL, Nicol JP. A research registry: uses, development, and accuracy. 7 Clin Epidemiol 1999;52:39-47.

20. Singal D, Brownell M, Chateau D, et al. Suicide and suicide attempts among women in the Manitoba Mothers and Fetal Alcohol Spectrum Disorder cohort: a retrospective matched analysis using linked administrative data. CMA7 Open 2017;5:E646-52.

21. Kogan MD, Martin JA, Alexander GR, et al. The changing pattern of prenatal care utilization in the United States, 1981-1995, using different prenatal care indices. 7AMA 1998;279:1623-8.

22. Kotelchuck M. An evaluation of the Kessner Adequacy of Prenatal Care Index and a proposed Adequacy of Prenatal Care Utilization Index. Am 7 Public Health 1994:84:1414-20.

23. Brownell MD, Ekuma O, Nickel NC, et al. A population-based analysis of factors that predict early language and cognitive development. Early Child Res $Q$ 2016;35:6-18.

24. Profile of the population, 2001 census [table]. Statistics Canada Data Liberation Initiative Table Name 95F0495XCB01002-Man.ivt. Ottawa: Statistics Canada; 2003.

25. Liang KY, Zeger SL. Regression analysis for correlated data. Annu Rev Public Health 1993;14:43-68.

26. Liu W, Kuramoto SJ, Stuart EA. An introduction to sensitivity analysis for unobserved confounding in nonexperimental prevention research. Prev Sci 2013;14:570-80.

27. Rosenbaum PR. Observational studies. 2nd ed. New York: Springler-Verlag; 2002.

28. Singal D, Brownell M, Chateau D, et al. The psychiatric morbidity of women who give birth to children with fetal alcohol spectrum disorder (FASD): results of the Manitoba Mothers and FASD Study. Can 7 Psychiatry 2017;62:531-42.
29. Heaman M, Tjaden L, Marzan Chang Z; PIIPC Research Team. Qualitative evaluation: Partners in Inner-city Integrated Prenatal Care Project in Winnipeg, Canada. Eur 7 Public Health 2015;25(Suppl 3):ckv171.031. doi: 10.1093/ eurpub/ckv171.031.

30. Astley SJ, Bailey D, Talbot C, et al. Fetal alcohol syndrome (FAS) primary prevention through FAS diagnosis: II. A comprehensive profile of 80 birth mothers of children with FAS. Alcohol Alcohol 2000;35:509-19.

31. Coyne KL, de Costa CM, Heazlewood RJ, et al. Pregnancy characteristics of women giving birth to children with fetal alcohol syndrome in Far North Queensland. Aust N Z 7 Obstet Gynaecol 2008;48:240-7.

32. Kvigne VL, Leonardson GR, Borzelleca J, et al. Characteristics of mothers who have children with fetal alcohol syndrome or some characteristics of fetal alcohol syndrome. 7 Am Board Fam Pract 2003;16:296-303.

33. Kvigne VL, Leonardson GR, Borzelleca J, et al. Alcohol use, injuries, and prenatal visits during three successive pregnancies among American Indian women on the Northern Plains who have children with fetal alcohol syndrome or incomplete fetal alcohol syndrome. Matern Child Health 7 2008;12(Suppl 1):37-45.

34. Brownell MD, Roos NP, Roos LL. Monitoring health reform: a report card approach. Soc Sci Med 2001;52:657-70.

35. Roos LL Jr, Nicol JP, Cageorge SM. Using administrative data for longitudinal research: comparisons with primary data collection. 7 Chronic Dis 1987; 40:41-9.

Affiliations: Department of Community Health Sciences (Singal, Brownell, Chateau, Roos), Department of Paediatrics and Child Health (Hanlon-Dearman, Longstaffe) and Manitoba Centre for Health Policy (Brownell, Chateau), University of Manitoba, Winnipeg, Man.; Department of Pediatrics (Wall-Wieler), Stanford University, Stanford, Calif.

Contributors: Deepa Singal and Marni Brownell conceived the study. Deepa Singal collected and analyzed the data and Elizabeth Wall-Wieler assisted with the analyses. Marni Brownell, Leslie Roos, Sally Longstaffe, Ana Hanlon-Dearman and Dan Chateau interpreted the data. All of the authors contributed to the design of the study, participated in the preparation of the manuscript, revised it critically for important intellectual content, approved the version submitted for publication and agreed to act as guarantors of the work.

Funding: Deepa Singal acknowledges receiving funding from Research Manitoba and the Evelyn Shapiro Award for Health Services Research in suport of her PhD dissertation.

Acknowledgements: The authors acknowledge the Manitoba Centre for Health Policy for use of data contained in the Population Health Research Data Repository under project 2013-036 (HIPC\#2013/201420), as well as Jennifer Enns for her comments on the manuscript. Data used in this study are from the Population Health Research Data Repository and were derived from data provided by the following institutions: Manitoba Health, Seniors \& Active Living, the Manitoba FASD Centre and the Winnipeg Regional Health Authority, Healthy Child Manitoba Office, Manitoba Families, and Manitoba Education \& Training. The results and conclusions are those of the authors, and no official endorsement by the Manitoba Centre for Health Policy, Manitoba Health, Seniors \& Active Living or other data providers is intended or should be inferred.

Supplemental information: For reviewer comments and the original submission of this manuscript, please see www.cmajopen.ca/content/7/1/ E63/suppl/DC1. 